\title{
Evaluasi Peningkatan Kinerja Produksi melalui Penerapan Total Productive Maintenance di PT Xacti Indonesia
}

\author{
Khalishah Livia \\ Departemen Manajemen, Fakultas Ekonomi dan Manajemen \\ Institut Pertanian Bogor \\ Kampus Dramaga Bogor 16680 \\ Pramono D. Fewidarto \\ Departemen Manajemen, Fakultas Ekonomi dan Manajemen \\ Institut Pertanian Bogor \\ Kampus Dramaga Bogor 16680 \\ e-mail: pramdfew@gmail.com
}

\begin{abstract}
Improvement of production perfomance in a manufacture industry is important to increase productivity. One way to increase production perfomance is through the implementation of Total Productive Maintenance (TPM). The purposes of this study are identifying the TPM implementation in PT Xacti Indonesia, calculating the production performance using the Overall Equipment Effectiveness $(O E E)$, and evaluating the factors causing low production performance and providing solutions for the improvement. The analytical method used is the Overall Equipment Effectiveness (OEE). The result of this study is the company has been implementing TPM, however there are still negligence of the operator in doing 55 and there are still some improvement to be made on the autonomous maintenance pillars implementation. The average value of OEE in January 2014 until January 2015 is $70.4 \%$. The low OEE value is caused by idle machine, the actual cycle time is high due to the lack of preventive maintenance and high downtime. Therefore, the solutions are training the operators about the 5S, increasing preventive maintenance activity correctly, and making a cleaning room to prevent machine breakdown.

Keywords: Maintenance, Overall Equipment Effectiveness (OEE), Performance measures, Total Productive Maintenance (TPM)
\end{abstract}

\begin{abstract}
ABSTRAK
Peningkatan kinerja produksi di industri manufaktur sangat penting dalam upaya peningkatkan produktivitas. Salah satu cara untuk meningkatkan kinerja produksi yaitu melalui penerapan Total Productive Maintenance (TPM). Tujuan penelitian ini, yaitu mengidentifikasi penerapan Total Productive Maintenance di PT Xacti Indonesia, menghitung kinerja produksi dengan menggunakan Overall Equipment Effectiveness (OEE), dan mengevaluasi faktor-faktor penyebab rendahnya kinerja produksi dan memberikan solusi perbaikan. Metode analisis data yang digunakan adalah Overall Equipment Effectiveness (OEE). Hasil dari penelitian ini, yaitu perusahaan telah menerapkan TPM, namun masih ada operator yang lalai dalam melakukan 5S dan pada implementasi pilar-pilar autonomous maintenance masih perlu dilakukan perbaikan. Rata-rata nilai OEE selama bulan Januari 2014 hingga Januari 2015 sebesar 70,4\%. Rendahnya nilai OEE disebabkan oleh mesin sering mengalami idle, waktu siklus aktual mesin tinggi karena kurangnya kegiatan preventive maintenance, dan tingginya downtime. Solusi perbaikan yang diberikan yaitu memberikan training kembali kepada operator tentang 5S, meningkatkan kegiatan preventive maintenance secara benar, dan dibuatnya cleaning room untuk sedapat mungkin menghindari terjadinya breakdown mesin.

Kata kunci: Overall Equipment Effectiveness (OEE), Pemeliharaan, Pengukuran kinerja, Total Productive Maintenance (TPM)
\end{abstract}




\section{Pendahuluan}

Globalisasi membuat persaingan diantara industri menjadi lebih ketat. Ketatnya persaingan memaksa para pengusaha untuk terus berupaya meningkatkan daya saing, dan hal ini juga terjadi pada industri elektronik. Upaya peningkatan daya saing juga menjadi tugas tersendiri bagi para Original Equipment Manufacturer (OEM). Para OEM dituntut untuk meningkatkan kemampuannya dalam memproduksi produk yang berkualitas tinggi, sehingga dapat menarik lebih banyak konsumen, yaitu para pemegang merek. Mereka juga perlu melakukan perbaikan terus menerus dan meningkatkan kinerjanya secara kontinu agar dapat terus bertahan di dunia industri.

Perusahaan yang mampu bertahan di industri salah satunya karena kemampuannya meningkatkan produktivitas. Menurut Triwardani et al. (2013), upaya peningkatan produktivitas dapat dilakukan dengan mengevaluasi kinerja produksi pada perusahaan. Prasetya dan Lukiastuti (2011) menjelaskan bahwa faktor kunci sukses dari setiap organisasi adalah pada kemampuannya dalam mengukur kinerja. Manajer tidak mampu menentukan bagaimana organisasi akan melakukan sesuatu dengan baik tanpa mengukur kinerja dengan tepat. Muis (2013) menambahkan bahwa produktivitas yang rendah mencerminkan kinerja yang kurang baik, begitu pula sebaliknya.

Upaya peningkatan kinerja produksi perusahaan salah satunya dapat dilakukan dengan menerapkan Total Productive Maintenance (TPM). TPM memiliki peranan penting dalam peningkatan kinerja produksi perusahaan, dan tujuan utama TPM yaitu mencapai zero breakdown dan zero defect. Upaya perusahaan mencapai zero breakdown dan zero defect dilakukan dengan melaksanakan kegiatan pemeliharaan menyeluruh baik secara mandiri oleh operator produksi (preventive maintenance), maupun oleh Bagian Pemeliharaan (breakdown maintenance). Kegiatan pemeliharaan ini ditujukan agar mesin-mesin produksi dalam kondisi yang selalu terjaga baik dan siap untuk mendukung aktivitas produksi, serta untuk menghindari munculnya produk cacat.

PT Xacti Indonesia (PT XI) adalah OEM yang memproduksi kamera digital. Proses utama yang dilakukan di PT XI adalah proses mounting, yaitu menempatkan komponen-komponen di Printed Circuit Board (PCB). Proses mounting di lini produksi-7 Digital Steel Camera (DSC Line 7) mengindikasikan adanya losses yang ditandai dengan adanya downtime yang cukup tinggi pada bulan Januari 2014 hingga Januari 2015 (Tabel 1).

Tabel 1. Nilai downtime mesin Mounter Section SMT (Januari 2014-Januari 2015)

\begin{tabular}{lc}
\multicolumn{1}{c}{ Bulan } & Downtime (menit) \\
\hline Januari 2014 & 5,008 \\
Februari 2014 & 5,810 \\
Maret 2014 & 5,889 \\
April 2014 & 5,673 \\
Mei 2014 & 4,854 \\
Juni 2014 & 1,923 \\
Juli 2014 & 600 \\
\hline
\end{tabular}


Lanjutan Tabel 1.

\begin{tabular}{lc}
\hline \multicolumn{1}{c}{ Bulan } & Downtime (menit) \\
\hline Agustus 2014 & 1,068 \\
September 2014 & 1,255 \\
Oktober 2014 & 779 \\
November 2014 & 598 \\
Desember 14 & 1,308 \\
Januari 2015 & 885 \\
\hline
\end{tabular}

Sumber: Departemen Produksi PT Xacti Indonesia (2015)

PT XI kehilangan 48,25 jam kerja selama Januari 2014 - Januari 2015 karena mesin rusak atau terganggu (down), dan hal ini berakibat buruk pada kinerja produksi, baik ditinjau dari sisi produktivitas maupun kualitas. Perusahaan mengklasifikasikan penyebab terjadinya downtime dalam waktu untuk melakukan perubahan model, mengatasi penggantian suku cadang (parts problem) dan kerusakan mesin, serta adjustment penyetelan mesin. Tingginya nilai downtime mengakibatkan kinerja produksi secara total menjadi rendah. Menurut Fahmi et al. (2012), data breakdown melalui pendekatan TPM dengan menggunakan metode OEE serta pengaplikasian delapan pilar akan mampu menjaga fungsi dari peralatan atau material pendukung kegiatan kerja. Disamping itu Permana dan Parkhan (2012) menyatakan bahwa upaya mengatasi rendahnya kinerja produksi dapat dilakukan dengan menerapkan TPM secara efektif, agar dapat tercapai peningkatan kinerja produksi secara optimal. Berdasarkan uraian-uraian tersebut, maka dalam penelitian ini ditetapkan tujuan sebagai berikut: (1) Mengidentifikasi penerapan Total Productive Maintenance (TPM) di PT Xacti Indonesia; (2) Menghitung kinerja produksi dengan menggunakan metoda Overall Equipment Effectiveness (OEE); (3) Merekomendasikan perbaikan kinerja produksi dengan pendekatan TPM.

\section{Metode Penelitian}

Kerangka pemikiran penelitian digunakan untuk menunjukkan arah bagi penelitian agar penelitian tersebut dapat berjalan sesuai dengan tujuan dan lingkup yang ditetapkan pada awal penelitian. Gambar 1 menunjukkan kerangka pemikiran yang digunakan pada penelitian ini.

Penelitian ini menggunakan data primer yang diperoleh melalui diskusi dan wawancara dengan manajer, asisten manajer, dan supervisor. Data primer berupa gambaran penerapan TPM di perusahaan dan indikator-indikator kinerja. Sedangkan data sekunder bersumber dari laporan produksi bulanan, serta maintenance schedule. Penelitian ini dilaksanakan di Section Surface Mounting Technology (SMT), Departemen Produksi PT Xacti Indonesia yang berada di Jalan Raya Bogor Km. 35, Tapos, Depok. Pengumpulan data pada penelitian ini dilakukan dari bulan Februari sampai dengan April 2015. 


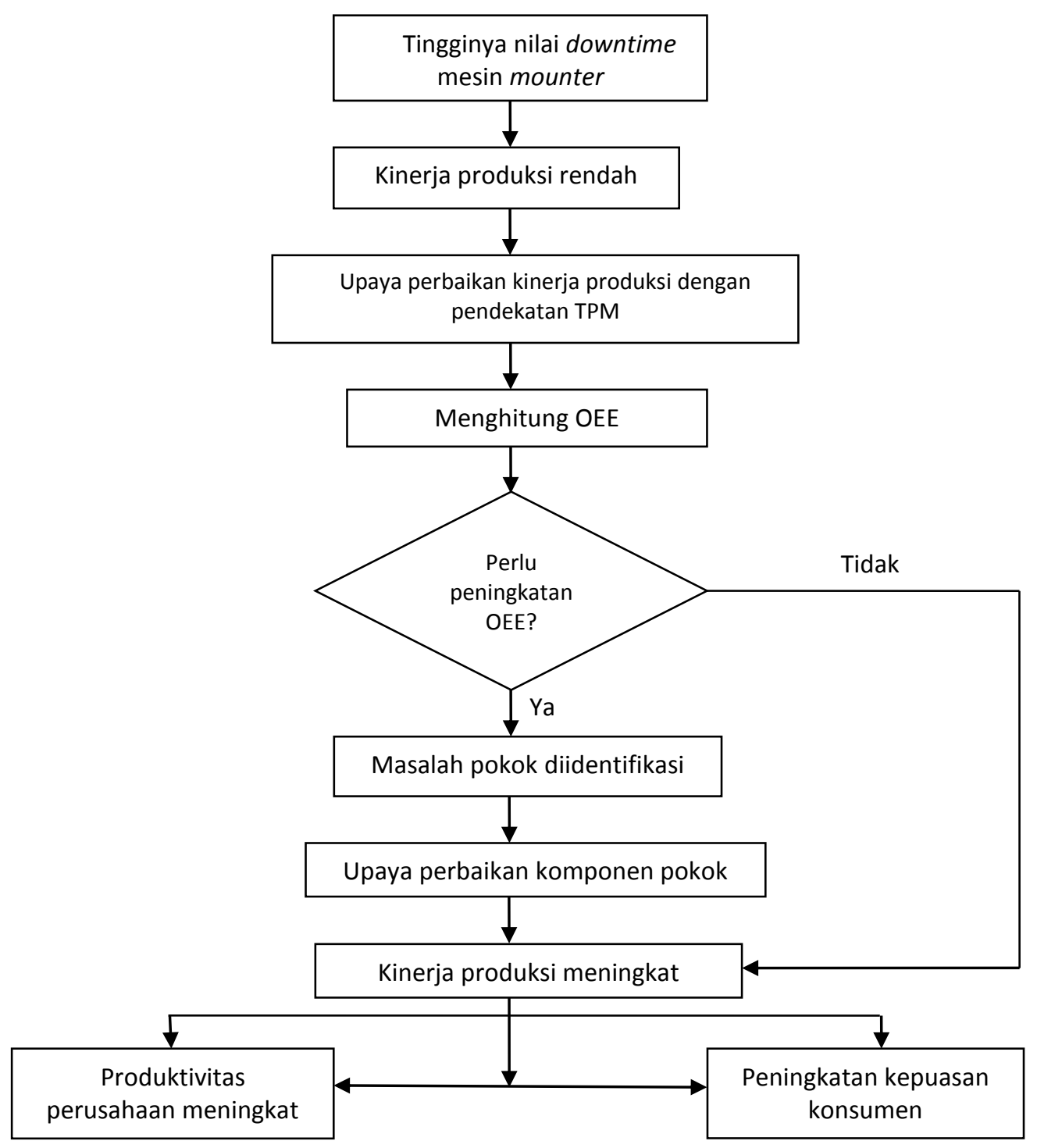

Gambar 1. Kerangka pemikiran

Tahapan penelitian diawali dengan mengidentifikasi permasalahan di PT Xacti Indonesia, yaitu rendahnya kinerja produksi perusahaan. Selanjutnya, dilakukan pencarian literatur dan kajian-kajian pustaka yang berkaitan dengan kinerja produksi perusahaan, yaitu literatur dan kajian tentang TPM. TPM dikenal juga sebagai pemeliharaan secara keseluruhan yang melibatkan partisipasi total dari manajemen level atas hingga karyawan produksi. TPM adalah suatu konsep program pemeliharaan yang melibatkan hubungan kerja sama yang erat antara pemeliharaan dan organisasi produksi secara menyeluruh yang bertujuan untuk mencapai zero breakdown dan zero defect (Nakajima 1988).

Langkah selanjutnya adalah merumuskan permasalahan yang dihadapi perusahaan dan menentukan ruang lingkup penelitian, lalu melakukan identifikasi terhadap penerapan TPM di perusahaan, meliputi bagaimana penerapan budaya kerja 5S (Seiri, Seiton, Seiso, Seiketsu, Shitsuke) dan pilar-pilar TPM. Pengumpulan data produksi menjadi langkah berikutnya, dan data produksi yang digunakan yaitu pada 
rentang bulan Januari 2014 hingga Januari 2015. Data tersebut diolah menggunakan pola TPM, kemudian ditentukan komponen mana yang menjadi pokok permasalahan yang membuat kinerja produksi menjadi rendah.

OEE dalam TPM adalah sebuah metode atau alat ukur yang dapat menggambarkan kemampuan mesin dan peralatan untuk menghasilkan produk yang berkualitas dalam total waktu yang tersedia secara maksimal. Ansori dan Mustajib (2013) menambahkan bahwa OEE merupakan metode yang digunakan sebagai alat ukur (metrik) dalam penerapan program TPM guna menjaga peralatan pada kondisi ideal dengan menghapuskan Six Big Losses peralatan. Menurut Nakajima (1988), formula matematis dari OEE dirumuskan sebagai berikut:

$\mathrm{OEE}=$ Availability (\%) $\times$ Performance efficiency (\%) $\times$ Quality rate (\%)

di mana:

1. Availability (ketersediaan waktu berproduksi), adalah rasio yang menggambarkan pemanfaaan waktu yang tersedia untuk kegiatan operasi mesin dan peralatan, Availability dipengaruhi oleh dua komponen, yaitu equipment failure dan set up and adjustment (penyetelan). Rumus availability adalah sebagai berikut:

$$
\begin{aligned}
\text { Availability } & =\frac{\text { operation time }}{\text { loading time }} \times 100 \% \\
& =\frac{\text { loading time-downtime }}{\text { loading time }} \times 100 \%
\end{aligned}
$$

2. Performance efficiency (efisiensi kinerja), adalah rasio yang menggambarkan kemampuan dari mesin dan peralatan dalam menghasilkan produk, yang dipengaruhi oleh idling and minor stoppage losses (menunggu dan berhenti sesaat) dan reduce speed (kecepatan menurun). Rumus performance efficiency adalah:

Performance efficiency $=\frac{\text { processed amount } x \text { theoretycal cycle time }}{\text { operation time }} \times 100 \%$

3. Quality rate, adalah rasio yang menggambarkan kemampuan mesin dan peralatan dalam menghasilkan produk yang sesuai dengan standar. Quality rate mencakup process defects (kerusakan karena proses) dan reduced yield (penurunan hasil) Rumusnya adalah:

$$
\text { Quality rate }=\frac{\text { processed amount }- \text { defect amount }}{\text { processed amount }} \times 100 \%
$$

Kondisi yang ideal untuk setiap komponen OEE pada suatu perusahaan adalah:

1. Availability $>90 \%$

2. Performance efficiency $>95 \%$

3. Quality rate $>99 \%$

Nilai OEE yang diharapkan > 85\% (Nakajima 1988).

Langkah selanjutnya adalah mengevaluasi komponen pokok untuk mencari penyebab utama rendahnya nilai komponen OEE, untuk kemudian ditentukan solusi untuk perbaikannya. Evaluasi terhadap penyebab rendahnya nilai komponen OEE dan 
alternatif solusi perbaikan dilakukan dengan cara brainstorming dengan pihak manajemen perusahaan dan menggunakan alat bantu Diagram Fishbone. Setelah alternatif solusi diperoleh, dipilih solusi perbaikan yang dapat diimplementasikan perusahaan. Pemilihan solusi perbaikan tersebut dilakukan melalui proses mencari akar masalah atau penyebab utama timbulnya masalah.

\section{Hasil dan Pembahasan}

\section{III.1. Penerapan TPM Section SMT}

PT Xacti Indonesia telah menerapkan TPM sejak tahun 2008 saat perusahaan masih bernama PT Sanyo DI Solutions Indonesia. TPM telah memiliki peranan penting bagi perusahaan, yaitu untuk meningkatkan kinerja dan produktivitas mesin. Selain itu, TPM dijadikan sebagai salah satu Key Performance Indicator (KPI) di Section SMT. Peranan penting yang diharapkan dari penerapan TPM adalah agar perusahaan selalu berupaya menjaga kondisi mesin dan peralatan tetap dalam kondisi baik, agar zero breakdown dan zero defect tercapai.

\section{Manajemen Pemeliharaan}

Aktivitas pemeliharaan di perusahaan ini telah terjadwal sehingga operator alat dan mesin serta teknisi Maintenance dapat melaksanakan tugasnya secara teratur dan disiplin sesuai dengan jadwal yang ada. Aktivitas pemeliharaan terdiri dari beberapa jenis, yaitu preventive maintenance dan corrective maintenance.

\section{a. Preventive maintenance}

Kegiatan pemeliharaan ini bertujuan agar mesin terawat dengan baik, sehingga selalu dalam kondisi siap pakai, dan dapat terhindar dari terjadinya kerusakan. Kegiatan Preventive maintenance untuk mesin mounter, terdiri dari:

1) Daily maintenance

Operator melakukan pemeriksaan terhadap mesin selama kurang lebih 5 (lima) menit sebelum digunakan untuk produksi. Kegiatan pemeriksaan, meliputi memeriksa tekanan udara, membuang sisa air dari mesin, membuang komponen yang mengganggu, dan membuang potongan-potongan sisa material produksi (tape).

2) Weekly maintenance

Pemeliharaan mingguan meliputi pembersihan monitor mesin, table, nozzle, dan filter yang memerlukan total waktu berkisar 100 hingga 150 menit.

3) Monthly maintenance

Kegiatan perawatan mesin produksi yang berupa pembersihan semua area mesin dan komponen-komponennya, mulai dari pembersihan nozzle, conveyor, pemberian pelumas (grease up) pada setiap komponen yang terjangkau. Kegiatan ini membutuhkan total waktu selama kurang lebih 200 menit.

Seluruh kegiatan preventive maintenance dilengkapi dengan check sheet (lembar pemeriksaan). Setiap kegiatan preventive maintenance yang telah dilakukan diberi tanda periksa pada check sheet, namun kondisi yang ada menunjukkan bahwa tidak semua kegiatan dalam instruksi kerja benar-benar dilakukan operator. Kurangnya supervisi membuat kegiatan perawatan pencegahan ini berjalan tidak maksimal, sehingga perlu adanya peningkatan supervisi atau pengawasan oleh 
Maintenance Supervisor untuk memudahkan evaluasi khususnya terhadap kegiatan preventive maintenance, dan TPM umumnya

\section{b. Corrective maintenance}

Kegiatan pemeliharaan ini bertujuan untuk memperbaiki mesin setelah mengalami breakdown (rusak) saat digunakan untuk aktivitas produksi. Kegiatannya berupa perbaikan peralatan atau komponen mesin, serta melakukan perbaikan terhadap hasil mounting (penggabungan komponen) yang tidak sesuai standar (Not Good/NG).

Data downtime akibat terjadinya berbagai jenis kerusakan mesin mounter selama periode bulan Januari 2014 hingga Januari 2015 disajikan pada Tabel 2. Tanggal, jenis kerusakan spesifik dan waktu produksi yang hilang (loss time) karena digunakan untuk melakukan perbaikan pada mesin mounter pada bulan Januari 2014, Februari 2014, dan Maret 2014 secara berturut-turut dapat dilihat pada Tabel 2, 3, dan 4 .

Tabel 2. Jenis kerusakan mesin mounter Section SMT bulan Januari 2014

\begin{tabular}{llcc}
\hline $\begin{array}{c}\text { Tanggal } \\
\text { kerusakan }\end{array}$ & \multicolumn{1}{c}{ Jenis problem/kerusakan } & $\begin{array}{c}\text { Frekuensi } \\
\text { Kerusakan }\end{array}$ & $\begin{array}{c}\text { Waktu perbaikan/ } \\
\text { kerusakan (menit) }\end{array}$ \\
\hline 2 Januari & Nozzle jatuh saat operasi berjalan* & 1 & 20 \\
30 Januari & Kabel sensor vertikal putus * & 1 & 120 \\
\hline & Total & 2 & $\mathbf{1 4 0}$ \\
\hline
\end{tabular}

Sumber: Departemen Produksi PT Xacti Indonesia (2014)

*dilaksanakan oleh teknisi khusus

Kerusakan pada bulan Januari 2014 tidak terlalu sering, yaitu hanya terjadi sebanyak dua kali dalam bulan itu. Waktu perbaikan tertinggi yaitu pada kasus kabel sensor vertikal putus $(85,7 \%)$, sehingga membuat total downtime pada bulan ini cukup tinggi (140 menit).

Tabel 3. Jenis kerusakan mesin mounter Section SMT bulan Februari 2014

\begin{tabular}{llccc}
\hline $\begin{array}{c}\text { Tanggal } \\
\text { kerusakan }\end{array}$ & \multicolumn{1}{c}{$\begin{array}{c}\text { Jenis problem/ } \\
\text { Kerusakan }\end{array}$} & $\begin{array}{c}\text { Frekuensi } \\
\text { kerusakan }\end{array}$ & $\begin{array}{c}\text { Waktu } \\
\text { perbaikan/ } \\
\text { kerusakan } \\
\text { (menit) }\end{array}$ & $\begin{array}{c}\text { Total waktu } \\
\text { perbaikan } \\
\text { (menit) }\end{array}$ \\
\hline 3 Februari & $\begin{array}{l}\text { Nozzle jatuh saat operasi } \\
\text { berjalan* }\end{array}$ & 1 & 20 & 20 \\
6 Februari & Holder nozzle glue bocor* & 1 & 120 & 120 \\
4 Februari & Tape putus saat operasi berjalan & 2 & 25 & 50 \\
7 Februari & Tape putus saat operasi berjalan & 3 & 25 & 75 \\
8 Februari & Tape putus saat operasi berjalan & 3 & 25 & 75 \\
9 Februari & Tape putus saat operasi berjalan & 2 & 25 & 50 \\
10 Februari & Tape putus saat operasi berjalan & 2 & 25 & 50 \\
11 Februari & Tape putus saat operasi berjalan & 3 & 25 & 75 \\
12 Februari & Tape putus saat operasi berjalan & 3 & 25 & 75 \\
14 Februari & Tape putus saat operasi berjalan & 3 & 25 & 75 \\
15 Februari & Tape putus saat operasi berjalan & 3 & 25 & 75 \\
16 Februari & Tape putus saat operasi berjalan & 2 & 25 & 50 \\
\hline
\end{tabular}


Lanjutan Tabel 3.

\begin{tabular}{ccccc}
\hline $\begin{array}{c}\text { Tanggal } \\
\text { kerusakan }\end{array}$ & \multicolumn{1}{c}{$\begin{array}{c}\text { Jenis problem/ } \\
\text { Kerusakan }\end{array}$} & $\begin{array}{c}\text { Frekuensi } \\
\text { kerusakan }\end{array}$ & $\begin{array}{c}\text { Waktu } \\
\text { perbaikan/ } \\
\text { kerusakan } \\
\text { (menit) }\end{array}$ & $\begin{array}{c}\text { Total waktu } \\
\text { perbaikan } \\
\text { (menit) }\end{array}$ \\
\hline 17 Februari & Tape putus saat operasi berjalan & 3 & 25 & 75 \\
18 Februari & Tape putus saat operasi berjalan & 3 & 25 & 75 \\
19 Februari & Tape putus saat operasi berjalan & 3 & 25 & 75 \\
20 Februari & Tape putus saat operasi berjalan & 2 & 25 & 50 \\
21 Februari & Tape putus saat operasi berjalan & 2 & 25 & 50 \\
22 Februari & Tape putus saat operasi berjalan & 1 & 28 & 28 \\
23 Februari & Tape putus saat operasi berjalan & 3 & 25 & 75 \\
24 Februari & Tape putus saat operasi berjalan & 3 & 25 & 75 \\
25 Februari & Tape putus saat operasi berjalan & 2 & 25 & 50 \\
27 Februari & Tape putus saat operasi berjalan & 3 & 25 & 75 \\
28 Februari & Tape putus saat operasi berjalan & 3 & 25 & 75 \\
\hline
\end{tabular}

Sumber: Departemen Produksi PT Xacti Indonesia (2014);

* dilaksanakan oleh teknisi khusus

Waktu perbaikan tertinggi terjadi pada bulan Februari 2014, yaitu pada perbaikan holder nozzle glue yang mengalami kebocoran walau kerusakan hanya terjadi sekali. Total waktu perbaikan terhadap kebocoran pada holder nozzle glue lebih rendah dibandingkan dengan total waktu perbaikan terhadap kerusakan berupa tape putus, yang frekuensi kejadiannya jauh lebih sering dalam bulan Februari 2014. Kejadian tape putus dalam satu hari dapat mencapai tiga kali. Total kejadian tape putus pada Februari 2014 adalah sebanyak 54 kali, dengan rata-rata loss time kurang lebih 25 menit per sekali kejadian kerusakan. Waktu perbaikan ini diatas standar waktu perbaikan untuk kasus tape putus yang ditetapkan perusahaan, yaitu selama 15 menit. Hal ini diperkirakan karena operator tidak mengikuti prosedur dalam melakukan perbaikan, yaitu tidak menggunakan alat yang berupa jigs.

Tabel 4. Jenis kerusakan mesin mounter Section SMT Maret 2014

\begin{tabular}{llccc}
\hline $\begin{array}{c}\text { Tanggal } \\
\text { Kerusakan }\end{array}$ & \multicolumn{1}{c}{$\begin{array}{c}\text { Jenis problem/ } \\
\text { kerusakan }\end{array}$} & $\begin{array}{c}\text { Frekuensi } \\
\text { Kerusakan }\end{array}$ & $\begin{array}{c}\text { Waktu perbaikan/ } \\
\text { kerusakan (menit) }\end{array}$ & $\begin{array}{c}\text { Total waktu } \\
\text { perbaikan } \\
\text { (menit) }\end{array}$ \\
\hline 1 Maret & Tape putus saat operasi berjalan & 2 & 25 & 50 \\
2 Maret & Tape putus saat operasi berjalan & 2 & 25 & 50 \\
3 Maret & Tape putus saat operasi berjalan & 2 & 25 & 50 \\
4 Maret & Tape putus saat operasi berjalan & 3 & 25 & 75 \\
5 Maret & Tape putus saat operasi berjalan & 1 & 30 & 30 \\
5 Maret & PCB transfer error* & 1 & 150 & 150 \\
6 Maret & Tape putus saat operasi berjalan & 2 & 25 & 50 \\
7 Maret & Tape putus saat operasi berjalan & 1 & 30 & 30 \\
10 Maret & Tape putus saat operasi berjalan & 1 & 30 & 30 \\
11 Maret & Tape putus saat operasi berjalan & 1 & 30 & 30 \\
12 Maret & Tape putus saat operasi berjalan & 2 & 25 & 50 \\
12 Maret & Pick up komponen error & 1 & 60 & 60 \\
13-Maret & Tape putus saat operasi berjalan & 1 & 25 & 25 \\
15 Maret & Tape putus saat operasi berjalan & 1 & 25 & 25 \\
\hline
\end{tabular}


Lanjutan Tabel 4.

\begin{tabular}{llccc}
\hline $\begin{array}{c}\text { Tanggal } \\
\text { Kerusakan }\end{array}$ & $\begin{array}{c}\text { Jenis problem/ } \\
\text { kerusakan }\end{array}$ & $\begin{array}{c}\text { Frekuensi } \\
\text { Kerusakan }\end{array}$ & $\begin{array}{c}\text { Waktu perbaikan/ } \\
\text { kerusakan (menit) }\end{array}$ & $\begin{array}{c}\text { Total waktu } \\
\text { perbaikan } \\
\text { (menit) }\end{array}$ \\
\hline 17 Maret & Pick up komponen error & 1 & 60 & 60 \\
18 Maret & Plastik tape terlepas & 3 & 15 & 45 \\
19 Maret & Plastik tape terlepas & 3 & 15 & 45 \\
20 Maret & Plastik tape terlepas & 3 & 15 & 45 \\
21 Maret & Plastik tape terlepas & 3 & 15 & 45 \\
24 Maret & Plastik tape terlepas & 2 & 15 & 30 \\
25 Maret & Plastik tape terlepas & 2 & 15 & 30 \\
26 Maret & Plastik tape terlepas & 3 & 15 & 45 \\
27 Maret & Plastik tape terlepas & 3 & 15 & 45 \\
\hline
\end{tabular}

Sumber: Departemen Produksi PT Xacti Indonesia (2014);

${ }^{*}$ Perbaikan dilakukan oleh teknisi

Kejadian tape putus terulang lagi pada bulan Maret 2014, namun frekuensi kejadian untuk kasus ini berkurang dibanding bulan sebelumnya, yaitu menjadi hanya sebanyak 19 kali. Hal ini terjadi karena pada bulan Maret 2014 perusahaan melakukan perbaikan, yaitu menambahkan tembaga pada tape agar tape lebih kuat dan tidak mudah putus.

Plastik tape terlepas merupakan jenis kerusakan lain yang perbaikannya cukup dilakukan oleh operator. Operator harus mampu mengganti dengan tape baru ketika plastik tape terlepas dengan standar waktu perbaikan berkisar 10 menit. Namun pada kenyataannya waktu perbaikan yang dilakukan operator mencapai 15 menit, melebihi standar waktu perbaikan, sehingga membuat downtime menjadi lebih tinggi.

\section{Evaluasi Jadwal Pemeliharaan}

Berdasarkan data kerusakan yang telah dibahas sebelumnya seperti apa yang tersaji pada Tabel Januari s/d Maret 2014, dapat diketahui bahwa total waktu downtime mesin pada rentang waktu tersebut adalah 2.728 menit atau setara 45,5 jam. Suatu nilai downtime yang cukup tinggi, sehingga perlu dilakukan evaluasi lebih lanjut untuk mengetahui rata-rata waktu kerusakan mesin ke kerusakan berikutnya melalui perhitungan Mean Time Between Failure (MTBF) pada setiap bulan. Berdasarkan penelitian yang dilakukan oleh Pujotomo dan Septiawan (2006), evaluasi MTBF digunakan untuk memperkirakan rata-rata rentang waktu mesin mengalami suatu jenis kerusakan dari suatu waktu ke waktu-waktu kerusakan berikutnya. Jika diketahui MTBF dapat ditetapkan tindakan perawatan untuk pencegahan, sebelum terjadinya suatu kerusakan.

MTBF adalah rata-rata waktu kegagalan mesin ke kegagalan berikutnya (Olofsson 2011), dimana formulasi perhitungannya sebagai berikut:

$$
M T B F=\frac{\text { total up time }}{\text { number of breakdowns }}
$$


Data yang dibutuhkan untuk mendapatkan nilai MTBF, meliputi data waktu operasi dan frekuensi kerusakan mesin dalam suatu periode. Hasil perhitungan MTBF mesin mounter untuk bulan Januari s/d Maret 2014 dapat dilihat pada Tabel 5.

Tabel 5. Perhitungan MTBF mesin mounter Section SMT (Januari 2014-Maret 2014)

\begin{tabular}{cccc}
\hline Bulan & Operation time (menit) & Frekuensi kerusakan & MTBF (menit) \\
\hline Januari 2014 & 22.287 & 2 & $11.143,50$ \\
Februari 2014 & 26.725 & 56 & 477,23 \\
Maret 2014 & 33.171 & 44 & 753,89 \\
\hline Total & 82.183 & 102 & $\mathbf{8 0 5 . 7 2}$ \\
\hline
\end{tabular}

Sumber: Data diolah dari Departemen Produksi PT Xacti Indonesia (2014)

MTBF unuk keseluruhan jenis kerusakan pada periode Januari s/d Maret 2014 kurang lebih 13,4 jam. Artinya rata-rata setiap 13,4 jam berpotensi untuk terhentinya kegiatan produksi karena terjadinya kerusakan. Hal ini mengindikasikan bahwa sistem perawatan mesin mounter masih belum optimal, karena waktu terjadinya kerusakan yang relatif pendek atau berdekatan. Perusahaan masih sangat perlu meningkatkan jadwal preventive maintenance pada periode produksi berikutnya. Peningkatan kegiatan perawatan tersebut, dapat berupa lebih sering melakukan pelumasan pada komponen (grease up), pembersihan, dan perbaikan ringan (penyetelan), agar dapat mencegah terjadinya kerusakan dini.

\section{Penerapan 5 S dan Pilar TPM Section SMT}

Filosofi dasar 5S (Seiri, seiton, seiso, seiketsu, dan shitsuke) harus diterapkan oleh seluruh karyawan perusahaan. Penerapan filosofi dasar $5 \mathrm{~S}$ ini dilakukan karena $5 \mathrm{~S}$ memiliki peranan penting dalam perusahaan, yaitu dapat meningkatkan efisiensi, produktivitas, kualitas, dan keselamatan kerja.

Prinsip dasar 5 S yang dilaksanakan di Section SMT, yaitu:

a. Seiri (ringkas), yaitu memisahkan barang-barang yang diperlukan dan membuang barang-barang yang sudah tidak diperlukan. Kegiatan ini, berupa tidak ada barang yang tidak berhubungan dengan pekerjaan di atas meja atau tempat kerja.

b. Seiton (rapi), yaitu penataan atau penyusunan barang-barang yang digunakan secara teratur. Kegiatan ini, berupa penempatan material ke rak sesuai dengan kode yang tercantum pada rak.

c. Seiso (bersih), yaitu mempertahankan kebersihan terhadap barang-barang yang digunakan oleh karyawan dan kegiatan ini, berupa adanya aturan kebersihan, seperti di mana yang harus dibersihkan, oleh siapa, dan jadwal pelaksanaannya.

d. Seiketsu (rawat), yaitu kegiatan yang ditunjukkan dengan bagaimana para karyawan mematuhi aturan (manual) dalam penggunaan alat-alat bekerja. Kegiatan yang dilakukan karyawan, yaitu setiap kali masuk ke ruang produksi karyawan harus menyentuhkan tangannya ke stand ground.

e. Shitsuke (rajin), yaitu kegiatan yang ditunjukkan dengan bagaimana para karyawan bekerja dengan disiplin dan menaati peraturan yang ada dalam perusahaan, seperti taat menaati larangan membawa handphone ke tempat bekerja. 
TPM yang diterapkan oleh Section SMT didukung dengan adanya pelaksanaan pilar-pilar TPM. Pilar-pilar ini, yaitu:

\section{a. Health and safety}

Pilar health and safety ditunjukkan dengan adanya Divisi K3 dari masingmasing section, termasuk Section SMT. Kecelakaan kerja dan gangguan kesehatan pada karyawan (operator) berpotensi untuk menyebabkan terjadinya kehilangan jam kerja. Kasus kecelakaan kerja terjadi pada 9 Januari 2014, berupa jari tangan kiri operator sobek karena terkena pisau cutter pada saat melakukan pekerjaan. Hal ini terjadi karena pisau cutter tidak memenuhi standar perusahaan. Tindakan yang diberikan oleh Divisi K3 yaitu segera membawa operator untuk mendapatkan penanganan medis di klinik yang tersedia.

\section{b. Education and training}

Bagi karyawan baru diberikan pendidikan dan pelatihan oleh Departemen Human Resource selama seminggu. Pendidikan dan pelatihan ini berupa pemberian pengetahuan tentang pentingnya implementasi ISO 9000, indoktrinasi kebijakan lingkungan, pelatihan $\mathrm{K} 3$, pemberian pengetahuan tentang moral etika bekerja, dan orientasi 5S, serta lainnya. Pendidikan dan pelatihan diarahkan untuk mencapai peningkatan produktivitas kerja.

c. Autonomous maintenance (AM)

Section SMT sudah menekankan autonomous maintenance pada seluruh operatornya. Ketika alarm menyala dari komponen atau mesin tiba-tiba berhenti, para operator dapat mengetahui bahwa itu merupakan tanda dari terjadinya potensi kerusakan mesin (error). Operator dapat pula melakukan pemeliharaan secara mandiri, misalnya membersihkan metal mask dengan alkohol dan mengaduk solder pasta agar tidak kental.

d. Planned maintenance (PM)

Tim PM di Section SMT terdiri atas tiga orang, yaitu seorang Asisten Manajer Area Maintenance dan dua orang teknisi. Mereka saling berdiskusi untuk melakukan troubleshooting sebelum melakukan rencana perbaikan. Awalnya tim ini melakukan analisis terhadap penyebab utama masalah pada mesin, kemudian apabila masalah sudah teridentifikasi tim akan menyusun rencana perbaikannya.

e. Quality maintenance (QM)

Pemeliharaan terhadap kualitas mesin mounter merupakan tanggung jawab Operator Area Maintenance. Kegiatan pemeliharaan ini dilakukan dengn pola preventive maintenance, baik berupa kegiatan pemeliharaan harian, mingguan, dan bulanan.

\section{f. Focused improvement}

Tim Planned Maintenance (PM) melakukan praktik perbaikan setelah melakukan troubleshooting. Perbaikan dilakukan terhadap bagian-bagian dari mesin mounter yang mengalami kerusakan, dan data kegiatan perbaikan dalam kurun waktu mulai Januari hingga Maret 2014 dapat dilihat pada Tabel 6. 
Tabel 6. Perbaikan mesin mounter Section SMT (bulan Januari 2014 s/d Maret 2014)

\begin{tabular}{|c|c|c|c|}
\hline Tanggal kerusakan & Jenis kerusakan & Perbaikan & $\begin{array}{c}\text { Waktu perbaikan } \\
\text { (menit) }\end{array}$ \\
\hline 2 Januari 2014 & $\begin{array}{l}\text { Nozzle jatuh saat operasi } \\
\text { berjalan }\end{array}$ & Menambah sensor di shutter. & 20 \\
\hline 30 Januari 2014 & Kabel sensor vertikal putus & $\begin{array}{l}\text { Mengganti sensor dan kabel } \\
\text { sensor. }\end{array}$ & 120 \\
\hline 3 Februari 2014 & $\begin{array}{l}\text { Nozzle jatuh saat operasi } \\
\text { berjalan }\end{array}$ & Menambah sensor di shutter. & 20 \\
\hline 6 Februari 2014 & Holder nozzle glue bocor & $\begin{array}{l}\text { Mengganti glue dan } \\
\text { membersihkan nozzle. }\end{array}$ & 120 \\
\hline $\begin{array}{l}4,7,8,9,10,11,12,14,15 \\
16,17,18,19,20,21,22,23 \\
24,25,27,28 \text { Februari } 2014\end{array}$ & $\begin{array}{l}\text { Tape putus saat operasi } \\
\text { berjalan }\end{array}$ & $\begin{array}{l}\text { Memperbaiki teknik } \\
\text { menyambung tape dengan } \\
\text { tepat. }\end{array}$ & 1.353 \\
\hline $\begin{array}{l}1,2,3,4,5,6,7,10,11,12 \\
13,15 \text { Maret } 2014\end{array}$ & $\begin{array}{l}\text { Tape putus saat operasi } \\
\text { berjalan }\end{array}$ & $\begin{array}{l}\text { Memperbaiki teknik } \\
\text { menyambung tape dengan } \\
\text { tepat. }\end{array}$ & 495 \\
\hline 5 Maret 2014 & PCB transfer error & Memasang stopper. & 150 \\
\hline 12 dan 17 Maret 2014 & Pick up komponen error & $\begin{array}{l}\text { Melakukan kalibrasi pada } \\
\text { kaset. }\end{array}$ & 120 \\
\hline $\begin{array}{l}18,19,20,21,24,25,26,27 \\
\text { Maret } 2014\end{array}$ & Plastik tape terlepas & Mengganti tape baru & 330 \\
\hline \multicolumn{3}{|c|}{ Total } & 2.728 \\
\hline
\end{tabular}

Sumber: Departemen Produksi PT Xacti Indonesia (2014)

\section{III.2 Perhitungan OEE}

Keberhasilan pelaksanaan TPM dapat ditunjukkan melalui indikator jumlah waktu yang bisa digunakan untuk kegiatan produksi, dan jumlah produk dengan kualitas standar yang mampu diproduksi. Dengan demikian besarnya nilai OEE pada salah satu mesin, bisa menjadi salah satu kriteria dalam melihat tingkat keberhasilan penerapan TPM di suatu perusahaan manufaktur. Kinerja produksi mesin yang diukur pada penelitian ini adalah kinerja mesin mounter di DSC Line 7 tipe Next Production Modular (NPM). Pengukuran kinerja mesin mounter melalui metode OEE ini mempertimbangkan tiga komponen, yaitu availability, performance efficiency, dan quality rate. Hasil perhitungan dapat dilihat pada Tabel 7.

Tabel 7. Hasil perhitungan nilai OEE mesin mounter Section SMT (Januari 2014-Januari 2015)

\begin{tabular}{lcccc}
\hline \multicolumn{1}{c}{ Bulan } & Availability (\%) & $\begin{array}{c}\text { Performance efficiency } \\
\text { (\%) }\end{array}$ & $\begin{array}{c}\text { Quality rate* } \\
\text { (\%) }\end{array}$ & $\begin{array}{c}\text { OEE } \\
\text { (\%) }\end{array}$ \\
\hline Januari 2014 & $\mathbf{8 1 , 7}$ & $\mathbf{7 5 , 6}$ & 99,0 & 61,1 \\
Februari 2014 & 82,1 & 80,7 & 99,0 & 65,6 \\
Maret 2014 & 84,9 & 81,2 & 99,0 & 68,3 \\
April 2014 & 83,9 & 81,6 & 99,0 & 67,8 \\
Mei 2014 & 85,7 & 79,4 & 99,0 & 67,4 \\
Juni 204 & 93,0 & 86,5 & 99,0 & 79,6 \\
Juli 2014 & 97,4 & 85,0 & 99,0 & 82,0 \\
Agustus 2014 & 95,4 & 94,7 & 99,0 & 75,5 \\
September 2014 & 95,4 & 79,9 & 99,0 & 69,1 \\
Oktober 2014 & 97,3 & 71,1 & 99,0 & 83,8 \\
November 2014 & 97,7 & 86,6 & 99,0 & 60,6 \\
Desember 2014 & 95,0 & 64,5 & 99,0 & 43,7 \\
Januari 2015 & 96,6 & $\mathbf{4 5 , 7}$ & 99,0 & $\mathbf{7 0 . 4}$ \\
\hline Rata-rata & $\mathbf{9 1 , 2}$ & $\mathbf{7 7 , 9}$ & $\mathbf{9 9 , 0}$ & \\
\hline
\end{tabular}

Sumber: Data diolah dari Departemen Produksi PT Xacti Indonesia (2015)

$* 1 \%$ reject (prediksi perusahaan) 
Nilai OEE selama bulan Januari 2014 hingga Januari 2015 fluktuatif dan rataratanya (70.4\%) masih dibawah kondisi ideal. Relatif rendahnya nilai OEE ini menunjukkan bahwa masih banyak perbaikan yang perlu dilakukan terkait pemeliharaan mesin dalam proses mounting pada periode produksi selanjutnya.

Nilai OEE yang rendah disebabkan oleh nilai dari dua komponen, yaitu availability dan performance efficiency, yang masih dibawah standar. Nilai availability pada bulan Januari 2014 rendah karena nilai downtime tinggi, meliputi waktu untuk adjustment, waktu yang diperlukan untuk penggantian model PCB, dan besarnya waktu untuk menangani mesin yang mengalami breakdown. Nilai performance efficiency yang rendah pada Januari 2014 terutama terjadi karena tingginya waktu mesin menganggur (idle), dan pada Januari 2015 kegiatan preventive maintenance tidak berjalan optimal, sehingga membuat waktu siklus aktual mesin tinggi.

\section{Analisis Penyebab Rendahnya OEE dan Solusi}

Nilai OEE yang dibawah standar disebabkan oleh rendahnya nilai komponen performance efficiency dan availability, sehingga perlu dilakukan analisis terhadap penyebab rendahnya nilai kedua komponen tersebut. Pada katagori Six Big Losses terdapat komponen yang mempengaruhi nilai performance efficiency, yaitu speed losses. Sementara komponen yang mempengaruhi rendahnya nilai availability, yaitu downtime.

Akar penyebab dari speed losses dan downtime dari masing-masing faktor dan pemilihan solusi perbaikan diurutkan berdasarkan jangka waktu pelaksanaannya, yaitu:

\section{a. Production Environment}

Akar penyebab dari rendahnya OEE terkait pada faktor ini adalah tidak difungsikannya cleaning room, sehingga debu dapat dengan mudahnya menempel di komponen-komponen mesin yang vital, menimbulkan gangguan operasional, dan akhirnya menimbulkan kerusakan mesin (breakdown). Perusahaan telah pernah mengupayakan untuk mengatasi masalah ini dengan mengoperasikan cleaning room pada saat perusahaan masih bernama PT Sanyo Solutions Indonesia. Namun alat-alat dan perlengkapan pada cleaning room telah banyak mengalami kerusakan, dan sampai sekarang renovasi dan penggantian perlengkapan pada cleaning room tersebut masih tertunda.

Solusi perbaikannya adalah membuat atau memfungsikan kembali cleaning room, dengan membuat partisi pada perbatasan pintu masuk dengan ruang produksi Section SMT. Disamping itu seluruh karyawan diwajibkan menggunakan seragam anti statik agar tidak banyak debu yang bertebaran ke mesin. Solusi jangka pendek adalah memperbaiki pelaksanaan budaya kerja 5S, dengan tidak membersihkan ruangan produksi Section SMT menggunakan sapu, karena debu yang berterbangan berpotensi menempel kembali pada mesin, sehingga lebih baik menggunakan vakum.

b. Man

Akar penyebab terkait pada faktor manusia adalah kebutuhan akan peningkatan pengetahuan, keterampilan, sikap dan perilaku kerja (kompetensi), sebagai akibat pesatnya perkembangan teknologi dan dinamika lingkungan usaha. Mengatasi kurangnya kompetensi yang dimiliki operator solusi perbaikan yang 
dapat dipilih adalah membentuk kembali tim Small Group Activity (SGA) sebagai wadah untuk berbagi pengetahuan, keterampilan dan pengalaman yang terkait dengan pengoperasian dan pemeliharaan mesin. Sebelumnya tim SGA ini sudah dibentuk dengan unsur dari masing-masing area di Section SMT, namun ketika perusahaan berganti menjadi PT Xacti Indonesia tim ini belum kembali aktif. Solusi lain adalah melaksanakan training melalui proses assessment yang menyeluruh dan mendalam untuk mendapatkan gambaran mengenai jenis, bentuk dan metoda pelatihan yang diperlukan untuk memenuhi kebutuhan kompetensi di masa yang akan datang. Pelatihan kepada teknisi yang menangani perbaikan secara khusus juga perlu mendapat perhatian, agar waktu untuk menyelesaikan perbaikan dapat ditekan.

c. Machine

Akar masalah ditinjau dari faktor mesin (speed losses dan downtime) yang berakibat pada rendahnya $\mathrm{OEE}$, yaitu kegiatan preventive maintenance tidak berjalan secara optimal. Preventive maintenance ditujukan untuk mencegah terjadinya kerusakan alat dan mesin dalam rentang waktu yang pendek, dibawah umur teknisya, sehingga diperlukan waktu perbaikan atas kerusakan (breakdown maintenance) yang lebih lama. Kegiatan preventive maintenance yang tidak optimal dapat diatasi dengan memperbarui prosedur operasional baku, instruksi kerja yang tertera pada checksheet schedule, jadwal, sosialisasi, pelatihan, dan pemantauan serta evaluasi yang teratur terhadap kegiatan preventive maintenance.

d. Method

Masalah utama yang berdampak pada rendahnya OEE dari terkait metode adalah pada ketersediaan manual inspection in line berupa aturan atau prosedur pemeriksaan (inspeksi) dan rule saat terjadi penggantian model produk (model change). Saat ini diperlukan waktu yang cukup banyak untuk melakukan penyesuaian jika terjadi perubahan model produk, sehingga waktu menganggur (idle) membesar pula. Untuk mengatasi masalah ini perlu dilakukan perbaikan sistem penggantian manual inspection in line yang lebih fleksibel, cepat, mudah diakses, dan mudah dipahami oleh karyawan apabila terjadi perubahan manual tersebut akibat perubahan model produk. Sistem inspeksi manual diganti dengan inspeksi secara otomatis (terkomputerisasi). Sementara itu untuk mengatasi belum adanya rule saat terjadi model change adalah dengan membuat rule baru, yaitu dengan memasukkan PCB model baru sesaat setelah PCB sebelumnya telah selesai beroperasi diproses pertama.

e. Material (komponen)

Penyebab dominan terkait material, yang dapat berkontribusi pada menurunnya nilai OEE adalah terjadinya kekurangan persediaan (shortage) komponen akibat sistem manajemen persediaan, dan keterlambatan kedatangan komponen. Terjadinya shortage akan mengganggu kelancaran produksi terutama ditinjau dari aspek kinerja (performance) dan karena kinerja menjadi salah satu dari tiga komponen dalam perhitungan OEE, maka dampak pada nilai OEE akan nampak. Perbaikan dalam sistem perencanaan persediaan (inventory), administrasi pergudangan dan material control, dan komunikasi dengan pemasok (supplier) 
adalah langkah-langkah yang bisa $\mathrm{p}$ diambil perusahaan untuk meningkatkan kinerja.

\section{Kesimpulan}

Berdasarkan hasil penelitian di atas, dapat disimpulkan bahwa penerapan TPM melalui implementasi budaya kerja $5 S$ dan pilar-pilar TPM, dan pola pemeliharaan mesin dan peralatan masih kurang efektif dalam mendorong kinerja produksi ke level yang ideal. Hal ini dapat ditunjukkan dengan rata-rata nilai OEE pada mesin utama (mounter) selama bulan Januari 2014 hingga Januari 2015, yaitu sebesar 70,4\%, dibawah standar menurut Japanese Institute of Plant Maintenance (JIPM) (> 85\%).

Rendahnya nilai OEE pada mesin mounter terutama disebabkan oleh rendahnya nilai komponen performance efficiency dan availability. Penyebab rendahnya performance efficiency adalah mesin sering mengalami idle dan waktu siklus aktual mesin tinggi, sehingga perusahaan perlu memberikan training kembali kepada operator dan meningkatkan kegiatan preventive maintenance secara benar. Sementara rendahnya nilai availability disebabkan oleh tingginya nilai downtime, sehingga perlu dibuat cleaning room untuk menghindari mesin breakdown. Perbaikan sistem perencanaan persediaan, pengadaan, dan administrasi pergudangan juga perlu perbaikan.

\section{Daftar Pustaka}

Ansori N, Mustajib MI. 2013. Sistem Perawatan Terpadu (Integrated Maintenance System). Yogyakarta (ID): Graha Ilmu.

Fahmi A, Rahman A, Efranto RY. 2012. Implementasi Total Productive Maintenance sebagai penunjang produktivitas dengan pengukuran Overall Equipment Effectiveness pada mesin Rotary KTH-8. Jurnal Teknik Unbraw [internet]. [diunduh 2014 Desember 10]; 1(1): 75-84. Tersedia pada http://digilib.ub.ac.id.

Muis M. 2013. Manajemen Sumber Daya Manusia pada Kinerja Industri. Bogor (ID): IPB Press.

Nakajima S. 1988. Introduction to TPM. Cambridge (UK): Productivity Press, Inc.

Olofsson O. 2011. Mean Time Between Failures \& Mean Time To Repair [Internet]. [diunduh 2015 Juni 12]. Tersedia pada: http://world-classmanufacturing.com/KPI/mtbf.html.

Permana D, Parkhan A. 2012. Pengukuran Nilai Overall Equipment Effectiveness (OEE) Di Lini Produksi Guna Mengoptimalkan Kinerja Peralatan (Studi Kasus Di PT. Muria Baru). Electronic Journal of Industrial research [internet]. [diunduh 2015 Januari 8]; 11(1): 1-12. Tersedia pada http://library.uii.ac.id.

Prasetya H, Lukiastuti F. 2011. Manajemen Operasi. Yogyakarta (ID): CAPS.

Pujotomo D, Septiawan H. 2006. Analisis total productive maintenance pada line 8/Carbonated Soft Drink PT Coca-Cola Bottling Indonesia Central Java. Jurnal Teknik Undip [internet]. [diunduh 2014 Desember 22]; 1(1): 1-15. Tersedia pada http://digilib.undip.ac.id. 
Triwardani DH, Rahman A, Tantrika CF. 2013. Analisis Overall Equipment Effectiveness (OEE) dalam meminimalisi Six Big Losses pada mesin produksi Dual Filters DD07. Jurnal Teknik UB [internet]. [diunduh 2015 Januari 8]; 1(1): 379-391. Tersedia pada http://digilib.ub.ac.id. 